\title{
RELATO POLICIAL Y EL CRIMEN QUE LO HABITA
}

\author{
Francisco de Undurraga \\ Universidad de Chile \\ fdeundur@uc.cl
}

RESUMEN / ABSTRACT

La aparición de publicidad y de novelas en serie en las portadas de periódicos franceses, a partir de 1836, marca la relación entre el género policial y los nuevos modos de visibilidad de la información en las sociedades industrializadas. Algunos ejemplos, tomados de un periódico de la época, la "Gazette des Tribunaux", permiten demostrar que la prensa estuvo desde sus comienzos vinculada a la literatura, si acaso no es una derivación de ella. E.A. Poe, creador del relato policial, conduce la retórica del morbo trabajada por Dante, Swift, Lautréamont y Baudelaire, de una apelación al lector, al orden del argumento y del procedimiento que lo estructura. En el relato policial conviven el discurso de lo que se cuenta, característico de la literatura, y el de la ciencia, pero solo en apariencia éste viene a suplantar a aquél, configurando de este modo su retórica.

PALABRAS CLAVE: relato policial, periodismo, retórica, literatura, crimen.

The emergence of publicity and of serialized novels in the covers of French newspapers, since 1836, characterizes the relation between crime story and new modes of visibility for information in industrialized societies. A few examples, coming from a journal of that time, the "Gazette des Tribunaux", allow us to demonstrate that journalism was from the beginning related to literature, if it is not a derivation from it. Edgar Allan Poe, creator of crime story, leads the rhetoric of morbid fascination developed by Dante, Swift, Lautréamont and Baudelaire, from an appeal to the reader, toward the order of argument and the procedure that provides its structure. In crime story the discourse of what is told, that characterizes literature, and the discourse of science, live together, but the latter takes the place of the former only apparently, shaping in this way its rhetoric.

KEY WORDS: crime story, journalism, rhetoric, literature, crime. 


\section{RELATO POLICIAL Y PERIODISMO: ¿GÉNERO(S) DEL SIGLO XIX?}

La historia de la relación entre relato policial y periodismo está marcada de asociaciones complejas, que son producto, en gran parte, de los nuevos registros y visibilidad que trae consigo el proceso de industrialización de los medios y su masificación. Más allá del juego de palabras, el asesino en serie, característico de esa etapa más reciente del género policial que es la novela negra, no es lejano a la emergencia de publicaciones en serie, en los periódicos de la primera mitad del siglo XIX. Numerosos elementos en común marcan los procesos de serialización de la producción en la era industrial, de tipificación del crimen, y la complejización de los dispositivos que conciernen a la prevención, detección y combate de éste, así como a la lectura que hace la población de todo esto. Habría una cierta relación entre estos procesos y la atracción que ejerce el crimen en el lector de relatos policiales, así como entre este tipo de atracción y la aparición de novelas en publicaciones periódicas y en serie, que trabajan la expectativa del lector de un ejemplar al siguiente -y cuya operación será incorporada con posterioridad en la literatura, a través del juego de tensiones, silencios y discontinuidades en un mismo texto, que trae consigo, por ejemplo, la narrativa de William Faulkner.

Las asociaciones complejas entre relato policial y periodismo están marcadas por los siguientes hechos: 1.- la aparición de la ficción en publicaciones periódicas, en tanto que práctica literaria a la cual tenían acceso más que nada los ilustrados, y presente en el mundo de las letras desde el Antiguo Régimen (Collins 89); 2.- estas novelas, que aparecen ahora en el "piso de abajo" de las portadas de periódicos, junto a la publicidad, que viene a financiar los mismos y a reemplazar las antiguas y onerosas suscripciones (Francia imita en esto a Inglaterra), así como la referencia a secas de los acontecimientos, sin adornos ni comentarios -todas innovaciones que trae Émile de Girardin a los medios franceses en 1836, que es el año en que funda el cotidiano parisino "La Presse" (88)- y que conforman ciertamente la protohistoria del Nuevo Periodismo de Truman Capote y Tom Wolfe, por allá por el año 1965 (Hartsock 195); 3.- el reemplazo de la ley marcial y de la tortura, por causa del asentamiento de los procesos democráticos y la aparición de cuerpos policiales que vienen a ocupar el lugar de las fuerzas militares, así como el surgimiento del detective (Haycraft 161-2); 4.- en este sentido, aquel factor inevitable del proceso de democratización, del cual 
la evolución del periodismo es a la vez reflejo y testigo, y que implica el paso, entre 1830 y 1880, en Inglaterra, de relaciones de poder político y del aparataje político de los notables, a la mercantilización de los medios, así como de los ideales radicales y liberales de educación, y de la concepción del lector como un pupilo, a la consideración de éste en tanto que consumidor (Palmegiano 141-2); 5.- las múltiples supresiones y reincidencias de la censura, a partir del siglo XVII en Inglaterra, y de la Revolución en Francia, sobre todo como medio de control fiscal y político; 6 .- la gestación del oficio del periodista: el periodista anónimo de la crónica británica y americana, y el ilustrado con un nombre en la prensa francesa (Collins 72); 7.- las estadísticas, que estructuraron las naciones modernas, así como las burocracias que las sostenían, y que constituyen -en una interpretación foucaultiana- junto a la ficción detectivesca, técnicas de vigilancia y mecanismos de una forma de poder disciplinaria (Copjec 170).

Los anteriores constituyen algunos de los elementos que marcan la relación entre el género policial y la aparición de nuevos modos de visibilidad de la información en las sociedades industrializadas, a partir de comienzos del siglo XIX. Detengámonos un momento en un ejemplo de publicación de la época, que no elijo al azar, sino porque aparece brindando la información del crimen, en aquel primer relato policial en la historia de la literatura: "Los Crímenes en la calle Morgue" (1841), de Edgar Allan Poe. Me refiero a la "Gazette des Tribunaux." Los archivos en microfilms de este periódico, en la sección Reserva de la Biblioteca Nacional de Francia, me han sido de extrema utilidad en este sentido.

En el "Prospecto" del primer ejemplar de la "Gazette des Tribunaux", del día martes 1 de noviembre de 1825, así como en numerosas de sus ediciones siguientes, encontramos permanentes referencias a las prácticas periodísticas británicas, así como al ejemplo que éstas significan para el desarrollo de las mismas en Francia. Más allá de este sensible reconocimiento al carácter arraigado de dichas prácticas del otro lado de la Mancha, en lo que concierne a la publicación periódica del crimen, la "Gazette" viene a llenar un vacío, se nos dice en el "Prospecto", en lo que concierne a la difusión de la magistratura, y de las decenas de casos que ésta revisa a cotidiano. Esto constituye, a juicio de los redactores, un aporte de primera importancia en materia de jurisprudencia -en particular, para "los abogados de las provincias más alejadas"- ya que se reunirán día a día "todas las causas que habrán sido juzgadas o alegadas la víspera anterior", en las distintas cortes parisinas (2), así como los más relevantes hechos de provincia y el extranjero. En 
el último ejemplar de cada año de magistratura (1 de noviembre al 31 de octubre) se publicará, además, una "Tabla general de materias" de las causas correspondientes a ese año, con tal de facilitar el acceso a las mismas.

La "Gazette" es también una instancia, señala el "Prospecto", de dar a conocer a los oradores de la magistratura, "entre los cuales figuran jurisconsultos de un alto saber, hombres hábiles en el arte de la palabra y jóvenes gentes llenas de ciencia y de talento" (1). Se trata, por otra parte, de un mecanismo de información para el público, respecto de aquellos "culpables habituales, [quienes] una vez que han cumplido sus penas y gracias al secreto de sus condenas, hacen sin cesar nuevas fechorías y [generan] nuevas víctimas". En este sentido, la "Gazette" podrá rendir un "verdadero servicio a todas las clases de la sociedad, sobre todo a los comerciantes" (1). La "Gazette" constituye así una de las primeras bases de datos de delincuentes, asesinos, infractores al derecho civil y comercial -uno de los primeros antecedentes, en este sentido, del Dicom chileno, y de otros instrumentos que vienen a desafiar, en la actualidad, los límites de la privacidad de los individuos.

Respecto a este tipo de "publicidad" en Inglaterra -en donde las prácticas periodísticas se remontan al menos al siglo XVII y cuentan con John Milton y su Aeropagita en defensa de la libertad de prensa (Palmegiano 140), entre sus precursores-el "Prospecto" afirma:

Se encontrará también en esta hoja la relación de lo procesos más extraordinarios relatados en los periódicos ingleses [...] Los periódicos ingleses consagran a menudo a los tribunales cuatro o cinco de sus inmensas columnas, y todos los hombres ilustrados consideran este reporte de los debates judiciales como una de las partes más útiles y las más importantes de la publicidad, no solamente en lo que concierne a las costumbres, sino también a la mejora social y de los medios que resultan de él para el descubrimiento de la verdad. Esto, ya que ocurre a menudo en Inglaterra que esta publicidad lleva ante los jueces a nuevos testigos [que] revelan hechos hasta entonces desconocidos $[\ldots](2)$

En la página 3 del segundo ejemplar de la "Gazette," del día jueves 3 de noviembre de 1825 , se señala que "el principio de la publicidad de los debates judiciales es llevado a un punto en Inglaterra, del que no sabríamos hacernos una idea [...]". Con los años, se irán agregando a la "Gazette" otras secciones, como "crónicas" y publicidad de distintos tipos. Desde la publicación de su 
primer ejemplar, la relación de los hechos, así como de los debates a los que éstos dan lugar, está hecha en un lenguaje que busca no solo la transmisión de los mismos al público, sino que dicha transmisión se lleva a cabo en la forma de una narración con diversos recursos literarios, e incluso, en ciertos casos, con un toque de ironía.

Respecto a esto último, está por ejemplo el caso -cito aquí uno de los cientos de miles de casos registrados en los largos años de publicación de la "Gazette des Tribunaux"- del caporal Rossi, registrado en la corte de apelaciones del Rhone, y recogido el 27 de junio de 1839, en el número 4304, año XIV de publicación de la "Gazette." Se titula "Noche de un caporal golpes y heridas" y aparece bajo la rúbrica "Justicia criminal". Se narran los hechos de la siguiente forma: "las noches de enero son largas; lo son principalmente para el cuerpo de guardias. Rossi, nacido bajo el bello cielo de Córcega, con la imaginación ardiente de su país, no podía comprender los tranquilos hábitos de sus camaradas..." En su noche de ronda, el caporal conoce a una mujer y termina "ensangrentado e inconsciente," luego de la golpiza que le da el novio de ésta.

En lo que concierne al uso del término "publicidad", según lo encontramos más arriba, es preciso hacer una distinción entre la labor de dar a conocer ciertas materias a la opinión pública, tales como los procesos y causas judiciales (que es el sentido que se da al término, en los pasajes citados de la "Gazette") - hay que ver, en cualquier caso, qué entendemos aquí por "opinión pública," y el acceso efectivo que los ciudadanos de la primera y segunda mitad del siglo XIX tenían a la "Gazette"- y la "publicidad" como práctica de financiamiento de este tipo de publicaciones, que empieza a generalizarse hacia mediados del siglo XIX. Pero así como diferenciamos uno y otro uso del término "publicidad", son precisamente los aspectos comunes de estas dos prácticas los que marcan el itinerario de un mismo fenómeno de divulgación industrializada.

"Publicidad," en tanto que comunicación a la comunidad, se vuelve históricamente inseparable de las herramientas económicas relacionadas con la "publicidad", en el sentido más actual del término, actividad esta última que hace posible la publicación a mayor escala de los periódicos, una vez que el sistema de las subscripciones se vio obsoleto. Esto, en particular, luego de la creación, en 1835, de Havas, la primera agencia de noticias, por el ex banquero del mismo nombre. El ejemplo lo seguirán Reuter, en Londres, y Bernard Wolff en Berlín, quienes fueron, en un primer momento, 
los asociados de Havas: "los tres acordaron dividirse el costoso negocio de cubrir el mundo" (Collins 88).

En el "Prospecto", la "Gazette" se declara expresamente independiente de partidos políticos, pero está también, en periódicos menos especializados de ambos lados del canal, la "publicidad" (damos con un tercer uso del término) que hacen de sí, de sus resoluciones y debates, los partidos políticos. Hasta 1830, nos informa Palmegiano, "los periódicos eran intensamente partisanos" (141). Las publicaciones que contenían material político eran objeto de fuertes impuestos. Si un periódico británico no contenía política, "no tenía que pagar el impuesto a la estampilla o el depósito de caución" (Collins 83). Sin embargo, señala Collins, esto favoreció la práctica de la "política entre líneas", acudiendo a menudo al relato de hechos del pasado, que fueran significativos para el presente: "metáforas, alusiones, insinuaciones forjaban [así] su camino a través de reseñas literarias" (83).

Ya se trate de la inserción de novelas publicadas en serie, en el "piso de abajo" de las portadas de los periódicos, ya de los giros propiamente literarios en una publicación más bien especializada, como es la "Gazette des tribunaux" -según nos muestra el ejemplo del caporal Rossi-ya de las reseñas literarias, que servían en Inglaterra a la divulgación política "entre líneas," vemos de qué manera la prensa estuvo desde sus comienzos vinculada a la literatura, si acaso no se puede decir que es directamente una derivación de ella.

No era preciso aguardar hasta 1965 y el Nuevo Periodismo para que dichos vínculos se hicieran explícitos o cobraran una forma de autoconciencia, ahora en un modo propiamente periodístico y a la vez literario -lo que Hartsock llama la "emergencia de una forma narrativa moderna". Ya Jonathan Swift, en la primera mitad del siglo XVIII, hacía propaganda política en panfletos, sirviéndose de ejemplos del pasado literario, que le permitían la elaboración de su sátira. Un siglo después, en 1815, los principales medios públicos de información seguían siendo "el púlpito, los panfletos y las baladas callejeras. El periodismo existía como una división de la literatura, aunque de rango inferior" (Palmegiano 141). La mala fama del periodismo en Inglaterra hizo que quienes contribuían con sus páginas se mantuvieran en el anonimato, a diferencia de los periodistas en Francia -hasta la época de Girardin-quienes no se limitaban al "news-gathering" (recolección de noticias) como sus pares ingleses, sino que contaban con un cierto prestigio de escritores.

Tony Hilfer señala que "la principal y decisiva característica de la novela de crimen es que en ella misma y en su mundo, la culpa y la inocencia son problemáticas. El mundo de la novela de crimen está constituido por lo que 
es problemático en él" (2). Publicaciones periódicas, como la "Gazette des tribunaux", utilizada por Edgar Allan Poe en el primer relato de crimen de la historia, y la cual se refiere a los "culpables habituales", respecto a quienes traerá una cierta visibilidad, antes inexistente, que beneficiará "a todas las clases de la sociedad, sobre todo a los comerciantes", es ya una forma de hacer problemático el tema de la culpa. O bien de llevar a la opinión pública el debate del crimen y de la culpa, más allá de los nuevos testigos que dicha divulgación pueda conducir a las cortes, para que presten sus declaraciones.

Antes que las cortes (de casación, de apelación, correccionales, militares, etc.), está sobre todo y cada vez más la comunidad, que echa mano de las noticias, gracias al despliegue editorial producido por la industrialización y la comercialización (la publicidad se ha integrado a ella) de los medios. Las publicaciones en serie, relativas a personajes de ficción que vienen a apelar al imaginario común, edición tras edición, ven sus fronteras confundirse con los relatos de aquellos individuos, marginales o no, de carne y hueso, que pueblan las páginas dedicadas al crimen, en los mismos u otros periódicos. Ambos tipos de relato, pero sobre todo el aparataje técnico e industrializado que los vuelve accesibles a la población -que les confiere una visibilidadcontribuyen a desmoronar las viejas transiciones entre los notables y los comunes, entre los intelectuales y las masas. Esta gran propagación de información, a la vez aúna y maquina el espíritu moderno en un mismo y complejo proceso de democratización de los usos y de las formas, y sobre todo de aquello que aparecerá ahora como determinante -y que concierne a las expectativas del lector-consumidor.

II

DANTE, SWIFT, LAUTRÉAMONT, BAUDELAIRE, POE Y LA RETÓRICA DEL MORBO

El trabajo de y con la expectativa del lector, quien aguardaba impaciente la continuación de la historia en la siguiente de las ediciones en serie, las cuales publicaron treinta y tres novelas de Balzac, durante la monarquía de Julio, así como Los Tres Mosqueteros y El Conde de Montecristo, de Alexandre Dumas, entre otras muchas novelas (Collins 89), organiza la persistencia y nuevas 
formas de un proceso que venía dándose en literatura desde Jonathan Swift, Dante, y seguramente desde antes. Este proceso dice relación con la retórica del morbo, y el acontecimiento relativamente reciente de su divulgación -a través del relato policial-así como de las modificaciones y agencias que esta divulgación significa para dicha retórica.

La escritura podrá intentar superar el "espesor de las imágenes" - contrarrestando la advertencia de Foucault, sobre el riesgo que corre la ficción de "depositar significaciones hechas [...] bajo las especies de un afuera imaginado" (21) - tanto en su modo literario como de las ideas, pero no se trata en ningún caso de su supresión. Vencer el espesor toma la forma del deseo y el trabajo de y con el espesor, y esto no es solo característico de la sátira swiftiana -es decir, de la difícil transcripción y metamorfosis del lenguaje natural y su tendencia a la parodia, de su cualidad comunicativa y escéptica, que suprime la gravedad en las palabras, para priorizar la espontaneidad y la experiencia, que no se contraponen en él- sino que la sátira viene, ya a comienzos del XVIII, a poner en evidencia este trabajo de y con el espesor, que pertenece al orden literario.

De alguna manera Vidocq, primer director de la "Seguridad Nacional", y uno de los primeros investigadores privados -se dice que Poe se habría inspirado en él, para la creación de su personaje Auguste Dupin (a pesar de que este mismo lo critica, en los "Crímenes" 425)- hace uso, en sus memorias, de un desprejuicio discursivo similar al de la sátira: la chispa en el lenguaje del hombre común toma ahora su lugar propio en el texto, lo vemos también en Conan Doyle, en Simenon. El desempeño de dicho desprejuicio en la página de la ficción ha estado siendo preparado, a la vez por el traspaso del lenguaje natural o cotidiano a la página escrita, que realiza el periodismo, y por las nuevas formas de difusión, producidas por el proceso de industrialización de éste.

En el relato policial se combinan dicha naturalidad en el uso de las palabras (el artificio de la literatura se hace ahora cargo de lo cotidiano) -lo que Raymond Chandler, al referirse a The Red House Mystery, de A.A Milnes, llama "una suavidad engañosa, que no es tan fácil como parece" (226) - y la retórica del morbo, que revisamos a continuación. "Arte horrible de justicia", "venganza de Dios", temor e invocación del dolor marcan el trabajo del morbo, en tanto que búsqueda de la complicidad del lector, en el Canto XIV $(6,16-18)$ del Infierno: "Oh venganza de Dios, cuánto debes / inspirar temor a aquellos que leen / lo que entonces apareció ante mis ojos!", exclama Dante al comenzar su narración del paso entre las bolas de 
fuego, enviadas por Dios para castigar a los blasfemos, en el séptimo círculo. Cinco siglos más tarde, e interpelando de igual modo al lector, Lautréamont (Ducasse) acude al mismo instrumento retórico, en las primeras líneas de sus Cantos de Maldoror:

Quiera el cielo que el lector, enardecido y momentáneamente feroz como lo que lee, encuentre, sin desorientarse, su camino abrupto y salvaje, a través de las ciénagas desoladas de estas páginas sombrías y llenas de veneno $[\ldots](23)$.

Lo mismo con Baudelaire, en su "Epígrafe para un libro condenado": "Lector apacible y bucólico, / sobrio e ingenuo hombre de bien, / bota este libro saturnino, / orgiástico y melancólico" (30). La advertencia que hace Swift al lector: "La sátira es una suerte de espejo en el cual los observadores descubren generalmente los rostros de todo el mundo, salvo el de ellos" ( $\mathrm{La}$ Batalla 158), y antes, La Rochefoucauld: "ponerse de partida en el espíritu que no hay ninguna de estas máximas que le incumba particularmente" (29), son en cierta forma antitéticas a la complicidad que se espera del lector en Dante, en Lautréamont y en Baudelaire.

En ambos casos -Dante, Lautréamont y Baudelaire, por un lado, y La Rochefoucauld, Swift y la sátira, por el otro- se trata de una persuasión negativa, en el sentido en que se incita al lector a adentrarse en la lectura, apelando, con los primeros, a su deseo de "temor," por lo "salvaje", el "veneno", lo "orgiástico" y lo "melancólico", y con los segundos, dando curso a esa función lúdica que lo invita a aventurarse en el texto, apelando a su curiosidad, al decirle que no será él el involucrado, poniendo en ambos casos a prueba las advertencias por parte del mismo. Como todo lo antitético, no existe aquí incomunicación. Se trata de dos formas de la retórica del morbo, ésa de que se acusa al relato detectivesco (Dubois lo llama "indiscreción" 28), y que consiste en uno de los mecanismos más efectivos, en lo que concierne a la divulgación y a la recepción sin precedentes de este tipo de literatura. Lo que sucederá con el relato detectivesco de Poe es que la apelación explícita al interés del lector, respecto a lo que el texto le prohíbe, se convierte en el trabajo de la contención a nivel del argumento. Veamos de qué manera.

La complicidad que Poe busca en sus apelaciones al lector es del orden de la confidencia y del testimonio, no de su interés respecto a lo prohibido: "la narrativa que sigue aparecerá al lector de alguna manera a la luz de un comentario sobre las proposiciones recién descritas", señala el narrador en los "Crímenes" (414). Lo mismo sucede en la mayoría de sus relatos: si 
acaso el narrador se dirige al lector en algún momento, lo hace en el modo de la confidencia y del testimonio, nunca de la complicidad mórbida. Ésta será tratada, por el autor, a través del desarrollo del argumento y el hábil trabajo de la contención que éste requiere. Ahora bien, no se trata aquí de cualquier argumento.

El aporte del autor a la literatura consiste precisamente en que el trabajo del deseo (o de la complicidad mórbida) está ahora centrado en la omnipotencia del procedimiento respecto al hecho inexplicable, desagradable o atroz. Quien decide respecto al procedimiento es el detective. El trabajo de contención, que reviste ahora la forma del procedimiento, es más que nada un trabajo de los personajes - a través de lo que no se dice de ellos- a diferencia de lo que se ha señalado en general sobre el género, que se reduce a una fórmula, y que no hay en él personajes. La "elucidación gradual del personaje" nos dice Chandler, "es todo lo que el relato detectivesco tiene el derecho de hacer" (236).

Al tema de la contención, y del paso de una retórica del morbo, en tanto que apelación explícita al lector, al orden del argumento y del procedimiento que lo estructura, se suma, según veremos, el del proceder discursivo de la ciencia. Si con la sátira el mecanismo de simulación y de disimulación, característicos del orden político maquiavélico, nos lleva a suspender el juicio, con la novela policial tradicional el juicio es finalmente afirmado, haciendo uso de otro tipo de simulación. Si la sátira simulaba estar de un lado y luego del otro de los argumentos, traspasándole finalmente la decisión al lector - puesto que el orden discursivo se ha vuelto indecidible- el género policial simula ahora echar mano del discurso de la ciencia. Llevar la investigación a término no es entonces más que detener la totalidad significante en un punto y hacer de éste la resolución del misterio. En otras palabras, se trata de la sanción del conocimiento positivo, que viene a desafiar y a imponerse por sobre el saber, en tanto que circulación de significantes.

La política, en otras palabras, ya no responde a una simple manipulación de apariencias -el certamen de los notables- porque con el advenimiento del orden moderno industrializado y la divulgación en serie, son sus propios mecanismos los que se afectan. En palabras de Caillois, "el placer que uno obtiene de una novela policial no es el de escuchar una historia, sino el de observar un truco "mágico", que el mago inmediatamente explica" (4) ¿Cuál es entonces la aventura estética y política que se desarrolla aquí, si el orden maquiavélico de las apariencias ha sido violentado y el reenvío a la totalidad 
significante es reemplazado por un texto que se detiene en una sola versión de sí mismo?

\section{LA OBRA, LA MUERTE Y LA TRANSMISIÓN DEL SABER.}

Si acaso es posible diferenciar las actividades en dos tipos -aquellas que resuelven problemas y aquellas que los denuncian- y el factor político de la literatura coincide con esto último, el género policial y la novela negra se vuelven particularmente problemáticos, ya que en ellos tanto el autor, el narrador como el lector, buscan resolver, a través de un medio concebido para denunciar. Esto es, en parte, producto del complejo proceso histórico de la industrialización de los medios y la masificación de la retórica del morbo. La era moderna e industrial se habría vuelto, en gran medida, la era de la resolución de problemas, más que de su meditación y denuncia, y esto marca el itinerario y la raíz anómala del género inventado por Poe. Recordemos que el autor venía saliendo del relato de horror, en busca, en cierta forma, del "equilibrio" de la razón. En términos de Haycraft, "ahora, a través de un proceso de racionalización comprensible y a la mano, la marioneta [el héroe de la ficción de Poe: él mismo] refleja los cambios en el maestro: éste se convierte en el perfecto razonador, la encarnación de la lógica, el campeón de la mente por sobre la materia" (164).

Si hay algo que afecta al conjunto de la literatura, y que dice relación con "la mente" que domina a "la materia", esto es el tema de la obra, la muerte y la circulación del saber, que no es un simple conocimiento de algo. Los siguientes versos de Fernando Pessoa nos hablan del reemplazo del saber por el conocer:

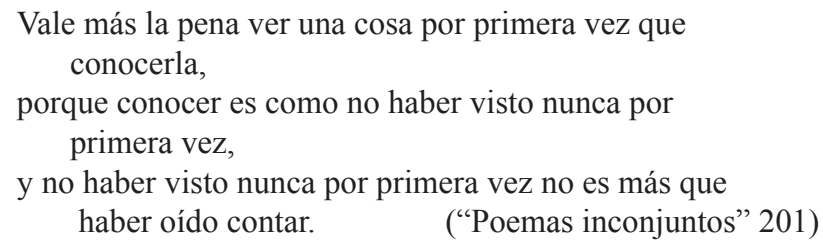

Digamos, a modo de hipótesis, que finalizar una obra es, entre otras cosas, entregarla al proceso de degradación interna que la habita. Como los seres vivos, la obra nace muriendo, o en cierta tensión con la muerte. La obra puede ser considerada un ser animado, por ejemplo, de acuerdo a la descripción que hace Aristóteles de la composición de la fábula, la cual debe ser "una 
y entera, como un ser vivo" $(23,1459$ a) y, más recientemente, de acuerdo a la idea de Cortázar, según la cual un cuento es "un organismo, un ser que respira y late, y [...] su vida consiste -como la nuestra-en un núcleo animado inseparable de sus manifestaciones" (35). Así como el autor debe engendrar la obra en tanto que criatura, éste enfrenta la lucha doble de la muerte en el proceso de su gestación, y de la radical indiferencia por parte de la obra, que hará posible que su creador suelte sus amarras.

Las teorías de los filósofos y las producciones escritas en general deben gatillar -su función es gatillar nuevas teorías y nuevas producciones orales y escritas. El hecho de haber sido enunciadas implica desde ya el término de algo y, de promover nuevas formulaciones, también el inicio de algo. El saber consiste precisamente en eso - de ahí sus vínculos con el lenguaje común- una cierta cualidad del relevo que permite a las palabras desestimar su asentamiento, puesto que lo que importa es la transmisión, y la nueva actividad argumentativa que tendrá a ésta por objeto. "Haber oído contar" es entonces, de acuerdo a las palabras de Pessoa, tan solo una parte del proceso. Recordemos cuando Lyotard nos dice que "el narrador actual puede ser él mismo el héroe de un relato, así como lo fue el antiguo" (40), lo que no es sino una invitación a concebir el orden literario, como el orden que hace que del lector dependan sucesos que ya no son simplemente escuchados, sino que él mismo los produce y encarna: el lector está en el lugar de los hechos, aunque haya mil años de por medio.

Ahora bien, al resolver y ya no solo denunciar, según veíamos, pareciera que el relato policial encara algo de manera definitiva. En otras palabras, pareciera que la relación fugaz de vida y muerte que habita el texto se agota en él, o que se la enfrenta desde el ámbito del conocimiento, más que desde el saber. Según plantea P. D. James, el relato policial tiene "una muerte en el corazón" (Hilfer 2). La restitución de la totalidad significante, que es la operación propia de la suspensión de la decisión, en la sátira, es decir, el texto que perdura y alimenta su artificio porque ha devuelto al lector su interpretación final, pareciera que ha detenido su audaz funcionamiento, al dar con algo cierto -al resolver el crimen/enigma. El cadáver es entonces algo más o algo menos para el texto que un inicio y una tensión para la acción dramática: el cadáver es el símbolo de la condición final que habita el relato detectivesco.

La literatura sintetiza el tiempo en su tratamiento de la alteridad, en su juego que nos permite ser otros y abrir el individuo a la comunidad. Si el tiempo es sintetizado en ella, hay un pequeño, imperceptible instante en 
que se acaba el tiempo. Es ese momento el que vuelca la obra hacia su degradación interna, a la necesaria muerte que la habita para hacer de ella un organismo. Pareciera que en el relato policial - $\mathrm{o}$ al menos en la abstracción que nos hacemos de él, puesto que siempre habrá un Conan Doyle, un Simenon y un Raymond Chandler- el tiempo ya no tiene su espacio, el tiempo que es el espacio en despliegue, o la luz que le da concreción y visibilidad, esa degradación interna ha cobrado en el relato policial una forma de superficie generalizada, un recorrido indicial y aventurado, en donde el celoso manipulador de argumentos -el autor- no deja lugar a la invariante indeterminación empecinada que caracteriza la marca del tiempo en la obra. Esto es lo que se da en la narrativa de William Faulkner, y también lo que Chandler define como la tarea del mejor escritor: escribir "escenas que pareciera que nunca fueron escritas antes" (235).

LA RAZÓN ES SENCILLA: EL CRIMEN ATRAE / EL CRIMEN ATRAE: LA RAZÓN ES SENCILLA.

Con Poe, su creador, decíamos, entendemos en qué medida el relato policial es una derivación del género fantástico, e incluso una reacción frente a esa rama del género fantástico que es el cuento de horror. Si el cuento de horror extrae de lo fantástico una realidad extraña, inaceptable o atroz, el relato policial es el esfuerzo para hacer esa misma realidad conmensurable, y a la vez para basarla -darle un asentamiento empírico en la experiencia social y cotidiana- no tanto en los sucesos que aparecen día a día en la prensa, como en el ánimo que el orden general y la posibilidad de dichos sucesos -las expectativas que toman ahora el lugar del orden indicial y superficie del mundo- han traspasado a la población.

Si hablamos de relato policial y de razón, diremos, ante todo, que la razón es sencilla: el crimen atrae porque es el único acto que podemos "resolver," en relación con la muerte. Y también, de manera inversa, el crimen atrae: la razón es sencilla y nos habla de su precariedad existencial. Más aún, para el razonador, venir al relato policial desde la teoría es abrir la nuez cefálica de la ficción, para encontrarse con una misma materia, mitad rancia y mitad desinhibida: ésta ha hecho del texto las dosis precisas, su desplante necesario para acaparar y proseguir con la atención comunitaria. Se trata, en otras palabras, del viejo asunto retórico de la dosificación, de la mesura, y del trabajo de/con la tensión, que cuenta ahora con la divulgación maquinista de los tiempos modernos. Ese mismo maquinismo vendrá a ser poetizado, 
en los extramuros del género, por un Baudelaire, por un Ezra Pound, por un T.S Eliot, por un Allen Ginsberg y un Ernesto Cardenal.

La precariedad, nos muestran el "whodunit” (“¿quién lo hizo?”), el relato "a cuarto cerrado", el cine negro y el "hard-boiled" (el relato "duro") norteamericanos, así como el "polar" francés, no es de la vida. Ésta siempre se impone, perdura -la literatura es el lugar en que la persistencia de la vida se verifica y resuelve, nos lo muestran los demonios de Milton, que han llevado consigo al castigo eterno, "this our spirit and strength entire / Strongly to suffer and support our pains" ("éste nuestro espíritu y resistencia entera / para sufrir y soportar con fortaleza nuestros dolores") (I, 146-7). La precariedad es en todos los casos la de nuestro rol sobre la escena, y la escena es la de la violencia de las grandes urbes (post)industriales, la de las policías corruptas e ineficientes (en el "hard-boiled", la corrupción, y en una primera versión, más "inocente" del género, la de Poe, la de Doyle, la ineficiencia de las policías), pero sobre todo la de la condición humana y sus reacciones ante un nuevo horizonte -el de la "destrucción de la experiencia", en tanto que "nueva morada del hombre" (Agamben 77), que la literatura ha tomado por tarea exhibir.

El relato policial, entonces, no solo resuelve, sino también exhibe, y esto marca el canon de (su) problemática -esa cuyos inicios fijábamos allá en dos fechas bastante exactas: 1 - el 1 de noviembre de 1825, en que el "Prospecto" a la primera edición de la "Gazette des Tribunaux" viene a fundar, de manera adelantada, el género policial, al hacer problemático el tema de la culpa, y al aportar con la visibilidad de los "culpables habituales", en beneficio de "todas las clases de la sociedad, sobre todo [de] los comerciantes"; 2- y 1836, que es el año en que Émile de Girardin funda el cotidiano parisino "La presse", y viene con ello a generalizar para el periodismo moderno las prácticas de la publicidad, el relato sin comentarios ni adornos, y la publicación de novelas en serie, en el "piso de abajo" de las portadas.

Respecto a la experiencia propiamente humana en el género -que es, tal vez, de lo que menos se ha hablado-podemos decir que hay dos elementos en común al teatro de la industrialización de los medios: 1- la certidumbre de que no es más que un teatro; 2- y que los individuos y la comunidad no estarán dispuestos a afrontar esta certidumbre, sino hasta recobrar un habla balbuceante, a tientas, cercana a los bebés, y a la inconmensurable expansión de las cosas (que son el tiempo, la luz o la visibilidad). Representación, voluntad y muerte aparecen así como los tres momentos en toda conflagración del delito. No se trata aquí de la voluntad que se impone, como de los dos 
sentidos en que la voluntad no es positiva: ésta no admite registro, y consiste más en una entrega que en un tomar la delantera -en esto radica la restitución del sentido o de la totalidad significante. Mal que mal, lo demuestra el género policial, no hubo jamás distinción entre lo sensible y lo inteligible. Todo lo que podemos esperar son porciones de aprensión a partir de, a través de, más allá y más acá de una inquietud y de una curiosidad que se despliegan tan materiales como inteligibles, tan entusiasmadas y fieles como lo que su propio retiro y su propio despliegue les permiten aprovechar. La razón teórica y la razón ficticia no son una excepción a este orden de lo común.

III

\section{RETÓRICAS PARA UN GÉNERO BALBUCEANTE. A MODO DE CONCLUSIÓN}

Lo que he hecho aquí es detenerme brevemente en los momentos de la gestación de un género, ahí donde el habla cobró de una vez y por todas un nuevo y no mencionado rumbo. Con el fin de encarar, a modo de conclusión, el tema de las retóricas para un género balbuceante, tomemos el ejemplo del habla de un niño.

Se trata de indagar en los mecanismos cómplices de la insistencia -en tanto que operación dominadora del "aquí estoy"- y la imitación, que es la operación en que el "yo" del "aquí estoy" deja su lugar a la cosa que es el saber, permitiendo una nueva instancia dominadora. La dominación, por tanto, no viene del "yo", sino de esa cosa que es el saber y de sus manifestaciones. En las transacciones de la insistencia y la imitación se combinan el interés y la entrega, el lucro y la observancia, la finalidad y la renuncia. Este funcionamiento cognitivo da su forma o estructura a la indecidibilidad ética, de la cual el género policial viene a ser algo así como su más acabada caricatura. La movilidad en el juego de las representaciones es lo determinante, llámese estética o política. "No se trata de asociaciones de ideas," nos dice Deleuze (44), sino de una movilidad en el juego de las representaciones. La imitación y la insistencia despliegan la configuración precaria de esta doble salvedad del juego que define el posicionamiento del poderoso. La apuesta del relato policial es optar por un aspecto de la salvedad, dando la apariencia e incluso la completa certidumbre de que se 
ha dado con algo cierto, cuando en realidad el juego de las representaciones sigue tan libre como siempre.

En el horizonte de la experiencia humana, el detective viene a ocupar el lugar del adivino (la pitonisa y el arte de la mantiké), apoyando su discurso en el del método deductivo de la ciencia, en tanto que resolución categórica del mundo y definición de verdades. El discurso de la ciencia -o bien los discursos sobre este discurso, que en verdad les escapa- se asienta(n) en y promueve(n) una nueva forma de transmisión, que ya no es la del relato que se cuenta, el "largo cuento" (Faulkner 204) de la literatura, de narraciones que se transmiten de una generación a otra -el narrador en tanto que "héroe de un relato, así como lo fue el antiguo", de acuerdo al planteamiento de Lyotard- sino de lo que se prueba. Ese es a la vez el lugar del quiebre y la apuesta del relato policial, ahí donde no solo conviven ambas formas de discurso -lo que se cuenta y lo que se prueba- sino que uno simula justificar al otro, aparentemente restándole su lugar. A pesar de que parezca que el discurso de la ciencia toma el lugar del otro, es en realidad el discurso de lo que se cuenta, el que saca partido de tal suplantación.

Es a través de este juego de simulación que se filtra "la venta" que el relato policial realiza al mundo, "en tanto que problemas en lógica y deducción" (Chandler 226). En las transacciones de la insistencia y la imitación que caracterizan las retóricas del género balbuceante-Poe nos insiste, en las tres largas primeras páginas de los "Crímenes", sobre el "poder del análisis" y la "cualidad de la observación"- se disimula la prioridad del lucro por sobre las prerrogativas de la literatura y su transmisión. A través del relato, y hasta cierto punto independiente de la transmisión, se comprueba, una vez más, la naturaleza compleja y precaria de la literatura, en que se combinan el interés y la entrega, la finalidad y la renuncia. A su vez, o más bien dando cuenta de su matriz común, en el paso fingido del discurso de lo que se cuenta al discurso de lo que se comprueba, sucede en el relato policial la operación económica, la transacción serial y mecánica que explicita su origen en y con el periodismo decimonónico.

Dorothy Sayers -en su ensayo clásico y, en la apreciación de Chandler, añejo, sobre el género policial- nos habla de lo favorable que se muestra el código legal británico, con su tradición de "juego limpio para el criminal", para la producción de la ficción detectivesca (75). Podemos agregar a esto, según hemos revisado, lo favorables que se muestran también, para dicha producción, las prácticas británicas del periodismo, el lugar y exposición con que ahí cuenta el crimen, desde temprano, y su influencia en el resto de 
los países, en particular, en Francia. Sayers dice que es un hecho que todos nosotros adoptamos una "actitud distante" (detached attitude) frente a un "buen asesinato" en el periódico (105). Chandler, por su parte, se refiere al "espíritu distante" (detached spirit) con que una novela de misterio es escrita. De otra manera, "nadie más que un psicópata querría leerla o escribirla" (233).

Esta actitud o espíritu "distante" con que Sayers califica nuestra disposición frente al crimen en la prensa, y Chandler, al crimen en la página de la ficción, caracteriza a la retórica del morbo, a través de la cual he tentado aquí una interpretación de los elementos discursivos propios del relato policial, así como de su matriz común con la producción periodística en serie. Un tercer elemento, que viene a contribuir con dicha interpretación, es la pretensión de objetividad que se da en ambos tipos de registro, en particular, luego del abandono de los comentarios y ornatos discursivos en el periodismo, hacia el año 1836. Wilkie Collins, nos informa Sayers, "aseguraba que casi todos sus argumentos se fundaban en hechos" (91). Recordemos, por otra parte, que el mismo Dashiell Hammett, antes de revolucionar el género por allá por los años 1930, se había desempeñado durante ocho años como detective en la agencia Pinkerton. Si hablamos, a su vez, de publicaciones de circulación masiva, así como de la incidencia de este fenómeno en el nacimiento del relato policial, no debemos olvidar que, a partir de sus 32 años, Poe se desempeñó como editor de la revista Graham's, y que “bajo su dirección editorial Graham's se convirtió en la primera revista de circulación en masa en el mundo, pasando en unos pocos meses de unos convencionales cinco mil lectores, a unos cuarenta mil sin precedentes" (Haycraft 160). En la misma Graham's, Poe publicó por primera vez, en 1841, su "Crímenes en la calle Morgue".

En lo que se refiere a sus conexiones con la ciencia -siempre más retóricas que realizadas, más deseadas que estrictas, y cuya circulación es ya una proyección de dicho deseo, que atrae al público lector: "un espacio de sutura", dirá Copjec (175), la "jouissance" lacaniana, releída por i ek para referirse al género (Rushing 3)- qué sucede, podemos preguntarnos, con las alusiones al método, sobre todo en Poe y en Conan Doyle ¿se trata, en particular en Poe, de las primeras demarcaciones, y de las huellas de las mismas, en el curso de su aventura por suelos desconocidos? Lo cierto es que, de tratarse de demarcaciones que dejan su huella, o en otras palabras, de la insistencia de la razón metódica característica del género, las referencias al método se convierten en uno de los Leitmotiv frecuentados por autores posteriores -aquellos seguidores, no de Poe, diremos, para desplazar el eje de 
las controversias, sino de Girardin, de Havas y de Jean Baptiste Joseph Breton (1777-1852), co-fundador, este último, de la "Gazette des Tribunaux".

¿No son las alusiones al método, lo claramente distintivo de aquella primera etapa, y lo que permite y constituye, en el horizonte del pensamiento y de la ciencia, un inicio de desacralización de esta última? El método del detective vuelve por primera vez pensable una naturaleza común para el orden preceptor de la poética, para los procedimientos de la ciencia y el orden conductual. Esto traerá modificaciones en nuestra percepción, en nuestro entendimiento y actividad, respecto a estas tres esferas de la experiencia. Los "realities" en la televisión de hoy constituirían precisamente otra fase, ajena y distante a la retórica del morbo, a la que me he referido aquí, puesto que ahora no se trata ya de la apariencia de deducción o de la simulación de la misma, que entusiasma y atrae, sino que de un simple engranaje, de una fórmula comercializada y de un comercio restringido a la fórmula de su expresión simplificada, ahora fuera de la página de la literatura, en un set y un montaje que se dicen "de la vida real".

Un proceso histórico y del pensamiento tiene lugar en la evolución del relato policial, y no solo los pormenores en los adelantos de un género. Por un lado, éste denuncia un estado de cosas, un síndrome del individuo y la colectividad moderna, mediante una forma de atractivo e interés. Por otro lado, a través del proceso de gestación, inauguración y participación en la cultura popular, el género vuelve operativa dicha denuncia, en un acto que, por lo mismo que significa la complacencia del lector en el voyeurismo y la ausencia de contenido de que se acusa al género, promueve una emancipación respecto al cientificismo imperante, desde comienzos del siglo XIX. En el intertanto, aparece el sujeto virtual y las nuevas versiones del género, anunciadas por la ciencia ficción de un Bradbury, y ya plenamente asimilados sus componentes detectivescos, en un Philip K. Dyck.

Con la ficción detectivesca se echa mano de la contención, la mesura -esas resistencias que han armado desde siempre la retórica y el discurso-y también de la simulación de la mesura, que es el mecanismo que establece nuevas toponimias y tensiones, con aquel fenómeno que acapara el interés desde la tragedia, y manifiesto sin duda en autores como Dante y Shakespeare: el crimen. No es el aparato raciocinante el que lleva a cabo la contención, sino su aspecto literario y discursivo -una retórica. El crimen que habita el relato policial no hace entonces, en cierto modo, más que sumar una estrategia, proponer nuevas partes a la poética, que son el aparato deductivo de la ciencia moderna, la figura del detective, las policías, etc. Vemos de qué 
manera la retórica requirió siempre de elementos históricos, que pasan a veces en silencio, pero que no por esto dejan de configurar sus partes, y hacen a la vez efectiva y expuesta la adhesión del lector / auditor.

\section{BIBLIOGRAFÍA}

Aristote. Poétique. Paris: Éditions Gallimard, 1996.

Agamben, Giorgio. Enfance et histoire. Destruction de l'expérience et origine de l'histoire.

Traduit de l'italien par Yves Hersant. Paris: Éditions Payot \& Rivages, 2002.

Baudelaire, Charles. Poesía completa. Edición bilingue. Madrid: Ediciones 29, 1997.

Caillois, Roger. "The Detective Novel as Game". The poetics of murder. Detective Fiction and Literary Theory. Edited by Glenn W. Most and William W. Stowe. New York: Hartcourt Brace Jovanovich publishers, 1983. 1-12.

Chandler, Raymond. "The Simple Art of Murder". The Art of the Mystery Story. A Collection of Critical Essays. Edited by Howard Haycraft. New York: Simon and Schuster, 1946. 222-237.

Collins, Ross F. "Traitorous Collaboration: The Press in France, 1815-1914". The Rise of Western Journalism, 1815-1914, Essays on the Press in Australia, Canada, France, Germany, Great Britain and the United States. Edited by Ross F. Collins and E.M. Palmegiano. Jefferson, North Carolina: McFarlan \& Company Inc, Publishers, 2007. 71-105.

Copjec, Joan. "The phenomenal nonphenomenal: private space in film noir". Shades of Noir. London: Verso, 1993. 167-197.

Cortázar, Julio. "El poeta, el narrador y el crítico". Edgar Allan Poe: Ensayos y críticas. Traducción, introducción y notas de Julio Cortázar. Madrid: Alianza Editorial, 1987.

Dante. La Divine Comédie. L'Enfer/Inferno. Présentation et traduction de Jacqueline Risset. Paris: Flammarion, 2004.

Deleuze, Gilles. Logique du sens. Paris: Les Editions de Minuit, 1969.

Dubois, Jacques. Le roman policier ou la modernité. Paris: Armand Colin, 2006.

Faulkner, William. As I Lay Dying. New York: Vintage International, 1990.

Foucault, Michel. La pensée du dehors. Paris: Éditions fata morgana, 1986.

"Gazette des tribunaux". "Prospectus", Mardi 1er Novembre 1825. Première année. Numéro 1er. Microfilm à la Bibliothèque Nationale de France, site François Mitterrand.

"Gazette des tribunaux". Jeudi 3 Novembre 1825. Première année. Numéro II. Microfilm à la Bibliothèque Nationale de France, site François Mitterrand.

"Gazette des tribunaux". 27 juin 1839. Quatorzième année. Numéro 4304. Microfilm à la Bibliothèque Nationale de France, site François Mitterrand.

Hartsock, John C. A History of American Literary Journalism. The emergence of a Modern Narrative Form. Amherst: University of Massachusetts Press, 2003. 
Haycraft, Howard. "Murder for Pleasure". The Art of the Mystery Story. A Collection of Critical Essays. Edited by Howard Haycraft. New York: Simon and Schuster, 1946. 158-177.

Hilfer, Tony. The crime novel. A deviant Genre. Austin: University of Texas Press, 1990.

Kracauer, Siegfried. Le roman policier. Un traité de philosophie. Traduit de l'allemand par Geneviève et Rainer Rochlitz. Paris: Éditions Payot \& Rivages, 2001.

Lautréamont. Les Chants de Maldoror. Préface et commentaires par Jean-Pierre Goldenstein. Paris: Pocket, 1999.

Lyotard, Jean-François. Lacondition postmoderne. Paris: Les Éditions de Minuit, 1994.

Milton, John. Paradise Lost. Edited by Scott Elledge. A Norton Critical Edition. New York, London: Norton \& Company, 1993.

Palmegiano, E.M. "The "Fourth Estate". British Journalism in Britain's Century". The Rise of Western Journalism, 1815-1914 (ver Collins). 139-172.

Pessoa, Fernando. Antología poética. El poeta es un fingidor. Edición y traducción de Ángel Crespo. Madrid: Espasa, 1997.

Poe, Edgar Allan. "The Murders in the Rue Morgue". Tales of Mystery and Imagination. Edited by Graham Clarke. London: Everyman, 2004. 411-444.

La Rochefoucauld, François de. "Réflexions ou Sentences et Maximes morales". Oeuvres Complètes. Paris: Garnier Frères, 1884.

Rushing, Robert A. Resisting arrest. Detective fiction and popular culture. New York: Other Press, 2007.

Sayers, Dorothy L. "The Omnibus of Crime". The Art of the Mystery Story. A Collection of Critical Essays. Edited by Howard Haycraft. New York: Simon and Schuster, 1946. 71-109.

Swift, Jonathan. "The Battle of the books". A Modest Proposal and other satires. Köln: Könneman, 1997.

Vidocq, Eugène-François. Mémoires de Vidocq. Chef de la Police de sureté. Tome Premier, Edito-Service S.A. Edition du Cercle de Bibliophile. Genève. 